\title{
Bush II
}

A ascensão neoconservadora ou o novo declínio?

\section{Cristina Soreanu Pecequilo*}

\section{Introdução}

Em novembro de 2004, o presidente George W. Bush foi reeleito para um segundo mandato à frente da Casa Branca, contrariando a expectativa e o desejo de muitos, dentro e fora dos EUA. Bem diferente das eleições de 2000, quando o pleito somente foi decidido por uma decisão polêmica da Suprema Corte Federal, meses depois, a disputa em 2004 transcorreu de forma relativamente tranqüila, com Bush conquistando sua vitória tanto no voto popular quanto no Colégio Eleitoral diante do candidato democrata John Kerry. Problemas em cédulas, máquinas de votação, registro de eleitores e longas filas de votação mais uma vez ocorreram, mas foram minimizados devido à margem de diferença maior que se estabeleceu entre os candidatos. Significativa, a participação popular atingiu níveis superiores a $70 \%$ dos eleitores registrados em alguns Estados, havendo um elevado número de novos eleitores votando pela primeira vez.

* Doutora em Ciência Política pela Universidade de São Paulo (USP), Professora de Relações Internacionais (Unibero), com bolsa de pesquisa Funadesp no projeto "Os EUA: dimensões de ação hegemônica". Professora de Relações Internacionais Faap/SP, Colaboradora Realnet/UnB e Pesquisadora Associada Nerinet/Ufrgs. Autora de $A$ política externa dos EUA (2003), Ed. Ufrgs, e Introdução às Relações Internacionais (2004), Ed. Vozes. Este artigo foi finalizado em 08/03/2005. E-mail: crispece@uol.com.br.

\begin{tabular}{|l|l|l|l|l|l|}
\hline Civitas & Porto Alegre & v. 5 & n. 2 & jul.-dez. 2005 & p. 353-380 \\
\hline
\end{tabular}


Mais do que nunca, a América queria decidir seus rumos, em meio a uma acirrada disputa pela hegemonia interna entre moderados e neoconservadores, acentuada nos últimos anos. Novamente, dotados de maior capacidade de organização e mobilização, os neoconservadores avançaram suas posições, consolidando seu domínio político sobre o sistema norte-americano. Bush conquistou $51 \%$ dos votos, Kerry recebeu $48 \%$ dos mesmos. Em termos numéricos, isso representou 58 milhões de votos para os republicanos, contra 55 dos democratas, que se traduziram em 286 e 252 votos eleitorais respectivamente. Igualmente, os republicanos preservaram e aumentaram sua maioria no Legislativo, na Câmara, 232 Republicanos, 201 Democratas, 1 Independente (e 1 cadeira em aberto) e no Senado, 55 Republicanos, 44 Democratas e 1 Independente. Nos governos estaduais, outra maioria republicana: 28 vitórias contra 22 dos Democratas.

Manteve-se a tendência observada em outras eleições, a de sustentação do controle prévio, com uma ampliação gradual de posições, também se repetindo o lado oposto desta mesma realidade: a de que uma parcela significativa da população dos EUA não valida esta agenda. Com isso, este novo avanço não deve obscurecer uma realidade bastante presente, que é evitada pelos republicanos, mas revelada pelos dados concretos: a existência de um país polarizado.

Apesar de Bush afirmar em seu discurso de aceitação da vitória que a sociedade norte-americana forneceu-lhe o capital político para agir, legitimando e dando continuidade, através de sua voz, a sua plataforma interna e externa, somente metade o fez. Porém, não há como se negar que o "momento político" atual, tanto em termos práticos, como subjetivos, favorece a consolidação republicana, que somente se expande a partir do posicionamento em postos chaves do sistema político, como mencionado.

Neste cenário, as opções de Bush II parecem indicar a preservação de suas prioridades já estabelecidas, dando seqüência à ascensão neoconservadora. Tal ascensão molda o mundo e os EUA, a partir de uma visão e valores bastante específicos sobre a América e seu papel, sinalizando uma unidade nacional irreal e um sucesso internacional controverso, com impactos diretos sobre a hegemonia e suas bases de poder. 


\section{A construção neoconservadora}

Para compreender o atual curso interno e externo da presidência Bush, e suas perspectivas neste segundo mandato, é necessário traçar o histórico da retomada neoconservadora. Minoritária dentro do partido republicano e no espectro geral da política dos EUA (situação semelhante da ala ultraliberal democrata), a linha neoconservadora que hoje está no poder é remanescente dos anos 1980 quando Ronald Reagan ocupou a Casa Branca por dois mandatos e de outros governos republicanos como Richard Nixon e Bush pai. Dentre estes, os mais conhecidos são Dick Cheney, Donald Rumsfeld, Condoleezza Rice, que na administração Bush são Vice-Presidente, Secretário de Defesa e Secretária de Estado, antes ocupando o cargo de Assessora de Segurança Nacional. Mesmo Collin Powell, tido como uma voz dissonante neste grupo, já tivera passagens pelo Executivo, em Bush pai e Clinton.

No contexto da Guerra Fria, e de uma hegemonia marcada pelas diversas crises dos anos 1970 (Vietnã, fim de Bretton Woods, expansão soviética e do terceiro mundismo, choques do petróleo), a presidência Reagan assume o governo com uma proposta de recuperação do país e de vitória sobre o adversário soviético. Destacando a natureza especial da América, a agenda de Reagan sustenta suas ações em uma renovação da força interna, construindo os preceitos do neoliberalismo que pregam a diminuição da intervenção econômica do Estado e a revisão de seus projetos sociais, visando a liberação das forças individuais e do mercado para a geração de prosperidade, cortando impostos e baixando juros. Outra fonte deste fortalecimento residia na recuperação dos verdadeiros valores e moral dos EUA, com um apelo às famílias, ao nacionalismo e à religiosidade, retrabalhando certos excessos da liberdade em direitos civis.

Externamente, a retórica era de cunho messiânico similar conclamando a união nacional para derrotar o comunismo, representado pelo "Império do Mal" soviético. Para isso, as prioridades eram o aumento dos gastos militares, incrementando a capacidade do exército convencional e investindo em projetos de alta tecnologia na área nuclear e no sistema de defesa antimísseis, conhecido como Guerra nas Estrelas (que quebrava o Tratado de Mísseis Anti-Balísticos assinado em 1972, segundo o qual ambas as potências comprometiam-se a manter sua vulnerabilidade a ataques nucleares externos). A partir deste aumento de capacidade bélica, seria possível impedir o avanço 
soviético em novas áreas, também garantindo o seu recuo e enfraquecimento em áreas tradicionais como a Europa Oriental.

Os EUA dispunham-se a ajudar grupos insurgentes dentro de diferentes nações por todo o mundo, desde que estes, independentes de sua motivação original ou perfil, estivessem dispostos a combater o comunismo abertamente. Identificados como freedom fighters (defensores da liberdade), estes grupos receberam desde treinamento militar pelos serviços de inteligência norteamericanos como CIA, como armamentos e ajuda financeira, destacando-se entre os mais conhecidos os contras da Nicarágua e Osama Bin Laden no Afeganistão. O objetivo destas interferências era provocar a desestabilização dos governos de esquerda ou próximos a Moscou, levando à mudança de regime nestas localidades.

Inicialmente bem sucedida no campo econômico, a Reaganomics, como ficou conhecida, provocou uma bolha de expansão e prosperidade, com a década de 1980 sendo marcada pela ascensão dos yuppies (jovens profissionais prósperos de Wall Street) e seu espírito competitivo e individualista. Contudo, a combinação de aumento de gastos com cortes de impostos levou a uma profunda crise orçamentária, elevando exponencialmente o déficit público, associado a um crescente desequilíbrio da balança comercial (os déficits gêmeos). Como resultado, observou-se uma perda de competitividade e recuo da economia, associado a um aumento da inflação, do desemprego e a diminuição dos índices de confiança dos consumidores. A crise manifestou-se de tal forma, que levou ao nascimento das teorias declinistas a respeito do fim da hegemonia norte-americana (as quais se opunham as visões de renovação pela reforma das prioridades), que somente foram superadas na segunda metade da década seguinte já no governo Clinton.

Em termos externos, contudo, a estratégia de Reagan alcançou maior sucesso à medida que exerceu pressões diretas sobre uma já fragilizada economia soviética, cujas reformas de Gorbachev apenas aprofundaram sua decadência, culminando com a sua queda e desagregação no período de 19891991. Aqui, temos dois períodos bastante distintos da ação externa: no primeiro mandato, 1981-1984, Reagan buscou o enfrentamento direto com os soviéticos, enquanto no segundo, 1985-1988, o diálogo marcou a relação entre as superpotências, diminuindo o nível de agressividade, com a adoção 
de um tom de conciliação. ${ }^{1}$ A mudança respondia à readequação da postura ao novo mundo e às condições domésticas norte-americanas de enfraquecimento o que, entretanto, não impediu que Reagan fizesse seu sucessor nas eleições de 1988, seu vice-presidente George Bush (a popularidade de Reagan e sua influência foram preservadas a despeito das crises e escândalos de sua presidência, o que o levou a ser chamado de Presidente "Teflon").

Para os neoconservadores a expectativa era de continuidade, ou seja, de manutenção das políticas prévias. Porém, a permanência do partido em Washington significou, na prática, um recuo desta ala mais radical e tradicionalista, uma vez que a presidência Bush mostrou-se mais próxima à linha moderada, interna e externamente. No campo interno, houve uma diminuição do nível de retórica religiosa e uma volta a uma postura mais equilibrada no que se refere a valores e direitos civis, sem tanto distanciamento com os democratas. Nas Relações Internacionais, o endurecimento de Reagan foi substituído por um processo de negociação com a União Soviética, dando continuidade ao padrão do segundo mandato do antecessor, sendo que a retórica cooperativa somente se aprofundou com o fim da bipolaridade.

Bush, mesmo com o envolvimento na Guerra do Iraque entre 1990-1991, sustentou a projeção de poder norte-americano no exterior por meio do internacionalismo multilateral vigente desde $1945 .^{2}$ Este internacionalismo foca o exercício da hegemonia no equilíbrio de hard e soft power na construção e manutenção de uma ordem internacional estável, consistindo-se no "estilo norte-americano" de domínio. ${ }^{3}$ Tal internacionalismo era o padrão predominante nesta presidência e seus assessores como James Baker, Lawrence Eagleburger e Collin Powell. O espaço dos neoconservadores foi diminuído, colocando-se em segundo plano suas tentativas de traçar rumos diferentes para o país no pós-Guerra Fria.

1 Historicamente, estas fases da Guerra Fria foram chamadas de Confrontação Renovada e Reaproximação.

2 Para uma descrição da evolução e perfil da presença internacional dos EUA desde sua independência em 1776 ver Pecequilo (2003).

3 Desenvolvida por Nye Jr (2002), esta classificação corresponde aos seguintes parâmetros de poder: hard power, recursos tangíveis e tradicionais como força militar, território, população e soft and co-optive power, poder econômico, tecnológico e ideológico, expressos de forma indireta na capacidade de convencimento e cooperação. 
Tais rumos foram expressos em um documento original do Pentágono, o Defense Planning Guidance (DPG) de 1992, que estabelecia a necessidade de revisão do engajamento externo com base na nova realidade de poder que emergira com o desaparecimento da antiga União Soviética: a do momento unipolar. ${ }^{4}$ De acordo com o DPG, os EUA, como única superpotência restante, deveriam aproveitar este contexto para avançar e consolidar ainda mais sua liderança no sistema internacional. As prioridades seriam a preservação da superioridade militar incondicional das Forças Armadas, o impedimento do surgimento de potências regionais rivais em quaisquer continentes (fossem elas amigas ou inimigas) e a conquista de novas áreas de influência que maximizassem o poder norte-americano. Isto representava uma expansão à Eurásia, domínio prévio soviético, tendo como objetivo a diminuição da vulnerabilidade estratégica do país por meio da obtenção de seus recursos naturais, principalmente o gás natural e o petróleo, assim como a construção de oleodutos e gasodutos na região ${ }^{5}$ que facilitassem o acesso a estas matériasprimas.

Entretanto, como mencionado, a então presidência Bush abafou esta agenda, considerando-a de teor agressivo e que poderia levar a um desgaste ainda maior das bases de poder, bastante afetadas pelas políticas econômicas dos anos 1980. Esta situação de declínio e mal-estar nacional, inclusive, foi a responsável pela derrota de Bush nas eleições de 1992 para Bill Clinton. Diante desta situação, Clinton colocou-se como o candidato da renovação e da mudança, prometendo dar mais atenção à agenda interna que à externa.

Os neoconservadores ficaram mais afastados do poder, o que não os impediu de continuar investindo em suas prioridades originais da Era Reagan. Ainda que estivessem ausentes da linha de frente da discussão do sistema

4 A expressão tem origem nos artigos de Charles Krauthammer em 1990 e será depois recuperada por outros intelectuais ligados aos neoconservadores como Robert Kagan e William Kristol (2000 e 2000b).

5 Embora esta questão sobre o avanço da presença norte-americana, inglesa e de suas companhias privadas ligadas ao setor energético tenha somente aparecido com maior destaque na mídia a partir de 2001 na presidência Bush, este processo já vinha se desenvolvendo há várias décadas. De acordo com Chalmers Johnson (2004), ele faz parte de um programa abrangente de ampliação da presença dos EUA no Oriente Médio e Ásia Central, por meio do acesso a seus recursos naturais e da abertura de bases militares norte-americanas em espaços anteriormente ocupados pelos soviéticos. 
político e dos principais cargos do governo, os neoconservadores construíram e solidificaram suas fontes de influência, reformatando seu posicionamento e programa de ação. Para isso, buscaram espaços alternativos, mantendo contínua a mobilização de suas bases em movimentos civis de cunho religioso, mídia e a sua proximidade com importantes setores privados como o energético e o complexo industrial militar.

Em termos eleitorais, até sua consolidação em 2000 e 2004, os avanços neoconservadores oscilaram entre altos e baixos, desenhando-se o início de seu crescimento a partir de 1994, já no mandato inicial de Clinton. Neste ano, pela primeira vez em várias décadas, nas eleições de meio de mandato, o partido democrata perdeu o controle do Congresso e não mais o recuperou. Na oportunidade, a "revolução republicana" foi liderada por Newt Gingrich e a plataforma do "Contrato com a América" prometia uma agenda de transformação nas áreas sócio-política e econômica, que não estavam sendo realizadas pela então presidência Clinton em seu primeiro mandato.

Apesar de ter sido eleito pela promessa da mudança, os dois anos iniciais da administração Clinton não avançaram projetos significativos que retomassem o crescimento econômico ou realizassem ajustes nos setores de saúde e previdência. Externamente, os democratas também não davam indicações de que retomariam a força da liderança, o que permitiu aos republicanos este crescimento. Para muitos, a vitória de Gingrich passou a representar a morte política de Clinton, considerando seu nome descartado para a reeleição.

Entretanto, a somatória de habilidade política e carisma do então presidente, associada a erros táticos republicanos que levaram à confrontação com o Executivo, reverteram esta situação (confirmando um dos mais conhecidos apelidos de Clinton "o garoto da virada"). Dentre estes erros, um dos mais conhecidos foi o episódio de paralisação das atividades federais em 1995 quando os republicanos bloquearam a votação do orçamento, legando a Gingrich uma imagem de radicalismo e antipatia. Clinton ainda foi favorecido pela retomada e consolidação da recuperação econômica neste mesmo ano e por um ativismo diferenciado em questões internas, com as respostas firmes ao atentado doméstico de Oklahoma.

Externamente repetiu-se inclinação similar com a intervenção em crises internacionais pendentes desde o governo anterior na ex-Iugoslávia. Fatores fundamentais adicionais foram a retomada da liderança nos órgãos multilate- 
rais como ONU e OMC e o bom relacionamento com as grandes potências e a atenção aos novos perigos à hegemonia, presentes desde 1993 com os primeiros ataques ao WTC e a seqüência de ameaças a alvos norte-americanos no exterior. Clinton, frente à elevação dos riscos do terrorismo internacional antiamericano, começou a investir mais diretamente no estudo e prevenção destes ataques em seu segundo mandato, sendo estes esforços coordenados por Richard Clarke e os demais serviços de inteligência como CIA e FBI. Clarke, posteriormente, será afastado de suas funções neste campo na próxima administração, passando a acusar a presidência Bush de displicência frente a esta ameaça, como será analisado.

Além disso, o Executivo promoveu mudanças em sua equipe internacional, dando-lhe maior firmeza e coesão. A principal troca foi a substituição de Warren Christopher por Madeleine Albright no Departamento de Estado, que passou a se referir aos EUA como "a nação indispensável”, ampliando a ação de importantes assessores como Anthony Lake. Lake, em 1993, à frente do Conselho de Segurança Nacional, havia sido o responsável pela criação da nova grande estratégia dos EUA no pós-Guerra Fria, o Engajamento e Expansão (E\&E). Naquele momento, o E\&E não obteve muito sucesso, consolidando-se a partir de 1995.

Considerado como uma política tradicional, mas ao mesmo tempo inovadora, o E\&E surgiu como a resposta democrata ao esgotamento da grande estratégia de contenção. Na prática, desde 1989, os EUA estavam buscando ocupar este vácuo em seu pensamento estratégico, mas Bush não conseguira fazer inovações neste sentido, apenas mantendo o curso do internacionalismo em uma administração pacífica e cuidadosa do cenário, não aceitando as recomendações do DPG. A postura de Bush ficou conhecida como status quo plus, justamente por esta ausência de transformações e de nova retórica, focando a ação norte-americana em áreas e temas conhecidos como Europa Ocidental, Otan (Organização do Tratado do Atlântico Norte) e Ásia, com algumas poucas ações renovadas para a promoção do livre comércio hemisférico (Iniciativa para as Américas) e o Nafta (Acordo de Livre Comércio entre os EUA, Canadá e México).

Por sua vez, o E\&E representou um salto qualitativo de estratégia, a despeito de inúmeras críticas que apontavam ser o novo programa de ação apenas uma recuperação mal elaborada de um dos princípios da contenção, a 
expansão das democracias e do livre mercado. Entretanto, esta expansão se daria de um modo bastante diferenciado, levando em conta a declinante realidade do poder norte-americano na década anterior, buscando consolidar a recuperação econômica desta fase e um novo modelo de presença externa. Não somente os temas tradicionais de política e estratégia seriam tidos como prioridades, como toda uma agenda econômica ligada ao fenômeno da globalização, buscando maior sustentação para a economia dos EUA. Tratava-se de uma estratégia readequada ao novo cenário pós Guerra Fria e de aceleração da transnacionalização e interdependência, associando a geopolítica a geoeconomia.

Em termos econômicos, a agenda possuía dimensões internas e externas, como o aumento da competitividade e produtividade interna, voltando ao mesmo nível dos aliados europeus e asiáticos no que se refere à tecnologia e eficiência. Adicionalmente, era preciso aumentar os mercados internacionais para a venda dos produtos norte-americanos, reequilibrando as contas externas e alimentando este processo de recuperação econômica. Para isso, era preciso incentivar o livre comércio por meio das negociações multilaterais da OMC, incrementando as propostas de integração regional na Ásia com a Cooperação Econômica da Ásia Pacífico (Apec) e Américas (Nafta e o lançamento da Alca, a Área de Livre Comércio das Américas). No campo de investimentos e finanças, a participação em ajuda externa seria aumentada, assim como a intervenção em crises financeiras internacionais, ajudando países como México, Rússia, Brasil e Coréia do Sul, reforçando os laços de interdependência destas nações com os EUA. Por fim, maior atenção seria dada a temas como direitos humanos e meio ambiente, reforçando a extensão global da presença dos EUA.

A presença residiria nesta base renovada de poder, mas administraria os custos dos compromissos internacionais em longo prazo, selecionando esferas de projeção e aumentando o compartilhamento de custos entre os aliados. A estratégia seria a do Engajamento Seletivo, preparando a transição da hegemonia em um mundo que possuía tendências multipolares derivadas do crescimento e fortalecimento da União Européia e da China.

Ainda que mantivessem sua presença e ação como construtores e mantenedores da ordem internacional, fortalecendo-a por meio da disseminação da democracia e do capitalismo, os EUA abririam espaço para um maior com- 
partilhamento de tarefas com as demais potências. As ações se dariam preferencialmente por meio de organismos internacionais (exercendo a liderança de forma alternativa e "engajando para conter" países em ascensão como a China), reforçando a interdependência entre os principais agentes internacionais. Igualmente visando reduzir custos, as Forças Armadas deveriam ser modernizadas para se tornar menores, mais eficientes e flexíveis, sem perder sua capacidade dissuasiva ou ofensiva. Atenção especial seria dedicada aos Estados Bandidos e Falidos (rogue and failed) dado seu potencial de instabilidade local, exercendo pressões políticas sobre os mesmos como Coréia do Norte, Irã e Iraque, e a perigos transnacionais como o terrorismo internacional e a proliferação das armas de destruição em massa (ADM).

Frente a esta recuperação interna e externa de Clinton, à perda de influência de Gingrich e de outros setores moderados do partido republicano, abriu-se mais uma brecha para o renascimento da linha conservadora. Outros pontos que favoreceram esta abertura foram o fracasso de Robert Dole, candidato republicano, nas eleições presidenciais de 1996, o risco de uma possível volta democrata ao domínio do Legislativo e à Washington em $2000 \mathrm{com}$ o vice-presidente $\mathrm{Al}$ Gore surgindo como candidato natural e favorito à sucessão de Clinton. Desta forma, visando voltar à Casa Branca em 2000, os moderados republicanos permitiram que os neoconservadores tomassem a frente das campanhas contra Clinton, o que levou à eclosão do escândalo Mônica Lewinski e o encaminhamento do processo de impeachment.

Mesmo sem apoiar completamente a perseguição moral a Clinton, impedindo o extremo de tirar o presidente do cargo, os moderados republicanos viram nesta movimentação a chance de criar espaços para conquistas eleitorais, de certa forma subestimando a força dos minoritários neoconservadores. Esta situação se revelou rapidamente em 2000 quando da estruturação e montagem do governo Bush, que sustentou sua base de apoio em suas figuras de confiança, descartando nomes moderados tradicionais do partido.

Do lado democrata, a ambigüidade marcou a reação ao impeachment e a Clinton. Embora se unissem para não permitir que o presidente fosse destituído, muitos passaram a ver Clinton como prejudicial a seus interesses eleitorais à medida que 2000 se aproximava. O medo de serem "contaminados" pelos problemas pessoais do presidente levou ao seu afastamento de várias campanhas, com resultados desastrosos. Apesar do caso Lewinski, o sucesso 
econômico de Clinton e o seu carisma, ainda faziam dele um governante popular, com alto índice de aprovação. Além disso, em meio ao vácuo de lideranças democratas existentes desde a década de 1990, Clinton era uma das poucas vozes que atraia a atenção do público. O caso mais conhecido desta estratégia equivocada foi a de $\mathrm{Al}$ Gore, que somente trouxe o presidente a sua reta final de campanha quando Bush filho ameaçava sua eleição, o que foi muito tarde.

Da mesma forma, os democratas acentuaram seu encolhimento e distanciamento do público ao não perceber as mudanças pelas quais passava a população dos EUA. Mesmo com a posição supostamente moralista assumida em relação a Clinton, as agendas dos democratas não respondiam às necessidades de uma grande parcela do país que percebia no discurso desta corrente uma baixa prioridade a suas demandas como melhor qualidade de vida, emprego e assistência médica, dando preferência a debates considerados "paralelos" nos direitos civis (minorias, aborto). Assim, este eleitorado tendia cada vez mais ao centro e à direita.

Estas mudanças de perfil eleitoral e demandas são resultado de uma série de transições internas, populacionais, étnicas, valorativas e econômicas, que corroeram a tradicional base de apoio democrata, mas que não foram percebidas adequadamente, a despeito das sinalizações pró-conservadores republicanos existentes desde 1994. Em contrapartida, este nicho foi aproveitado pelos neoconservadores que, administrando seus radicalismos, apresentaram uma plataforma mais condizente com esta nova América em formação. Aprofundava-se, assim, a disputa entre moderados e neoconservadores, que culminou com a eleição de Bush em 2000 e em sua reeleição em 2004.

Analisando estas transformações, observou-se um crescimento de minorias, principalmente a hispânica, que buscam sua inserção plena à promessa do sonho americano e em estados mais pobres do Sul, os industriais (focados na siderurgia em sua maioria) e os agrícolas do meio oeste, afetados diretamente pelas políticas de modernização e abertura comercial da Era Clinton. Para esta parcela da população, a recuperação econômica da década de 1990, sustentada na globalização e abertura comercial, que elevou as pressões por competitividade e diminuição do protecionismo representou uma diminuição da renda e dos níveis de emprego. 
Associada à manutenção e elevação de impostos, essa dinâmica levou à perda de espaços e a maiores dificuldades, o que reforçou a sensação de perda de lugar no mundo e de exclusão, que teve como contrapartida um aumento do tradicionalismo no campo valorativo e do nacionalismo. Para a maioria desta população, o programa doméstico democrata é encarado como excessivamente liberal e intervencionista em alguns temas, não se identificando plenamente com debates sobre direitos civis de minorias, homossexuais, controle da posse da armas e impostos, apresentando ainda um viés mais religioso. Nestes setores, a tolerância ao comportamento de Clinton e à agenda democrata era menor. $\mathrm{O}$ incentivo a movimentos fundamentalistas cristãos e nacionalistas reside nesta dinâmica, como revelam atentados como o de Oklahoma e o aumento da ação destes setores em escolas, partidos, dentre outros (defendendo, por exemplo, a obrigatoriedade da reza em escolas, a abolição de certos temas de ensino como a teoria de Darwin).

Em tal contexto, o grupo de Bush demonstrou-se mais hábil em apresentar propostas que atraíram esta parcela da população, também se beneficiando dos já mencionados recuos moderados dentro do próprio partido republicano e dos democratas. Paradoxalmente, a agenda foi montada de forma tão eficiente que atendia aos desejos tanto da parcela da minoria hispânica que crescia, como dos grupos acima mencionados, de origem branca, e situados tanto no espectro mais rico, quanto no mais pobre da população. O que parece indicar uma contradição (a união de parcelas opostas de sociedade em torno da mesma agenda) provocada por esta mensagem de centro e de inclusão da plataforma neoconservadora. Além disso, esta plataforma se beneficiou da própria figura de Bush, que apresentou um discurso direto, simples, bem-humorado, reconhecendo suas falhas, e de tom populista.

Na campanha eleitoral de 2000, estas propostas vieram à tona em forma de dois conjuntos de iniciativas, que retomavam os preceitos já descritos da Era Reagan e do DPG. No que se refere à política doméstica, apresentou-se a visão do "conservadorismo com compaixão" (compassionate conservantism), no qual se prometia a recuperação moral e valorativa da América, assim como a liberação dos esforços individuais dos cidadãos, declarando-se favorável à manutenção da posse de armas pela população e ao corte de impostos. Habilmente, os neoconservadores defenderam sua agenda social de forma centrista, não exibindo radicalismo em temas polêmicos como aborto, direitos civis das minorias e educação sexual. A estratégia era demonstrar que Bush, pessoal- 
mente, era um homem de fé, contra o aborto e os excessos da sociedade norteamericana, mas que, como presidente, não interferiria no processo legal que garantia estes direitos a todos. A escolha, neste sentido, seria preservada. Igualmente, os neoconservadores rejeitam este termo, autodefinindo-se como moderados de centro. Assim, evitavam-se os extremos e se conquistavam mais votos dos eleitores moderados e centristas, insatisfeitos com a paralisia democrata e seu relativo descaso com suas reivindicações.

No campo internacional, a retórica do Internacionalismo Diferenciado criticava as presidências anteriores, inclusive a de Bush pai, pela complacência na condução da liderança dos EUA. Desde o fim da Guerra Fria, as Forças Armadas haviam sido abandonadas a sua própria sorte, segundo este argumento, passando por um processo de desmonte que fragilizava a capacidade defensiva e de ataque do país. Era preciso recuperar o setor de Defesa por meio do aumento de gastos no setor convencional e investindo num projeto fundamental, mas abandonado ao longo dos anos: o sistema de defesa antimíssil (TMD). Além disso, era essencial reposicionar os EUA no mundo, dotando-o de um comportamento adequado com sua realidade de poder. Definida como a única superpotência restante, a nação norte-americana não poderia subordinar seus interesses a instituições e acordos multilaterais e deveria comandar os processos de uma posição avançada. Adicionalmente, a vulnerabilidade energética precisava ser superada, com a conquista de novas regiões estratégicas na Eurásia, reconfirmando as avaliações prévias.

$\mathrm{Na}$ mesma linha, a superioridade do país precisava ser reafirmada diante de aliados e inimigos tradicionais, não havendo "parceiros", e sim "competidores" estratégicos aos interesses nacionais. Dentre estes, Rússia, China, Japão e UE destacavam-se, havendo ainda uma marcante preocupação com as nações falidas e bandidas, cujas práticas agressivas não seriam mais toleradas ou compensadas por meio de negociações políticas. Como única opção, era necessária a sua transformação em nome da democracia e da segurança, produzindo a mudança de regime por meio de intervenções militares ou políticas, de forma a eliminar seu risco como patrocinadores e santuários de oponentes da América.

A política e o poder dos EUA são percebidos de forma tradicional, sustentados nos recursos mais tradicionais como força e militarismo, com baixa ênfase em mecanismos de dominação alternativos como regimes e organizações, focando-se nos aspectos interestatais. Comparado ao internacionalismo multilateral vigente pós-1945 trata-se de uma quebra tática em direção ao unilatera- 
lismo/isolacionismo, lembrando os primeiros anos de existência da nação norte-americana: um padrão que considera que os EUA devem agir no mundo sem amarras de forma a não restringir sua margem de manobra ou delegar sua segurança, vontade e interesses a outros.

Tal agenda interpelou uma parcela significativa da população, suficiente para levar Gore à derrota em 2000, em meio a todas as controvérsias sobre o Colégio Eleitoral, cédulas e votos, culminando na decisão da Suprema Corte Federal que proibiu a recontagem dos votos na Flórida. ${ }^{6}$ Ganhando no voto popular, mas perdendo no Colégio, Gore foi derrotado por Bush em sua campanha à Casa Branca, dando início ao processo de real consolidação da agenda neoconservadora. Finalmente, depois de cerca de duas décadas, o comando do país voltava a esta corrente, com a conquista do Executivo, a maioria na Câmara e o equilíbrio no Senado.

\section{O primeiro mandato (2001-2004)}

Contando com o apoio de apenas metade dos EUA e beneficiado por uma decisão legal e um sistema de eleição indireta instaurada no século XVIII, George Bush tomou posse em janeiro de 2001. Apesar desta relativa falta de apoio entre a população, os republicanos logo de início começaram a implementar sua plataforma de maneira decisiva, abandonando a moderação da campanha e as promessas de não interferência, principalmente no campo dos direitos sociais e civis. As primeiras movimentações foram a de desviar verbas de programas de educação sexual e aborto para iniciativas religiosas e de abstinência sexual. Além disso, Bush promoveu um amplo corte de impostos, aumentando os gastos com defesa, passando do superávit da Era Clinton ao déficit fiscal.

6 Gore perdeu a eleição por ter sido oficialmente derrotado por Bush na Florida por 537 votos. Esta vantagem garantiu a Bush os votos eleitorais deste Estado, levando à conquista do Colégio Eleitoral com 271 votos contra 266 de Gore e 1 abstenção. Na contagem popular, Gore obteve 50.999.897 votos contra 50.456.002 de Bush, respectivamente 48,38\% e 47,87\% (o restante coube ao candidato independentes Ralph Nader que, em muitas localidades, significou a derrota de Gore). Legislativo: Câmara 221 republicanos, 212 democratas e 2 independentes. Senado, inicialmente, 50 republicanos e 50 democratas. Com a deserção do republicano James Jeffords de Vermont, os democratas conseguiram a maioria, 51-49, que somente se manteve até as eleições de 2002 quando os republicanos conquistaram mais cadeiras e solidificaram a sua maioria (www.fec.gov). 
Externamente, similar agressividade foi apresentada, abandonado o Tratado de Kyoto, reafirmando a oposição ao Tribunal Penal Internacional, iniciando o TMD, e colocando-se em rota de colisão com as potências aliadas da UE, a China e a Rússia. Rapidamente, os protestos foram grandes dentro e fora dos EUA, gerando um sentimento de desconforto e mal-estar crescente que se refletiam na queda de popularidade interna e no isolamento na arena internacional. Temas econômicos relativos à $\mathrm{OMC}$, projetos de integração regional foram colocados em segundo plano, revertendo o curso de Clinton, dando preferência à expansão de acordos bilaterais com países menores.

Porém, a equipe de Bush e a Casa Branca, demonstravam coesão e firmeza, destacando-se os já mencionados nomes de Dick Cheney, Donald Rumsfeld e Condoleezza Rice, compondo este grupo que ficou conhecido como os falcões neoconservadores. Powell, no Departamento de Estado (DOS), em contrapartida, era um dos poucos moderados, atuando como mediador no sistema internacional, ainda que suas decisões e ações fossem sempre superadas por seus demais colegas no Departamento de Defesa (DOD) e Conselho de Segurança Nacional (NSC). No campo interno, figuras como John Ashcroft também se destacavam por sua postura neoconservadora à frente do Departamento de Justiça, com inúmeras denúncias de desrespeito a direitos civis sendo colocadas.

Seguindo de forma polêmica, mas com coerência diante das promessas de campanha, a Casa Branca enfrentou estas inúmeras dificuldades e protestos nestes meses iniciais de governo, sem abrir mão de sua agenda. Entretanto, um acontecimento inédito pareceu trazer-lhe uma inflexão: 11/09/2001. Neste dia, pela primeira vez em sua história, os EUA foram atacados em seu território continental por um grupo terrorista, atingindo duas de suas principais cidades e símbolos de poder: as torres gêmeas de Nova Iorque e o Pentágono em Washington. Realizado de maneira simples, com o seqüestro de aviões de carreira, os atentados foram eficientes em destruir a última sensação de normalidade que permanecia no mundo, colocando em questão o poder militar da superpotência restante. Percebido por muitos como uma resposta a Bush, os ataques, contudo, eram parte de um processo de longo prazo muito maior, característico de contestação hegemônica.

Já em 1993 o WTC havia sido atingido como outros alvos norteamericanos no exterior, como indicado, o que levou a presidência Clinton 
naquela época a iniciar estudos mais aprofundados sobre o terrorismo internacional e seus riscos. A Al-Qaeda de Osama Bin Laden, um ex-aliado e "defensor da liberdade" da Era Reagan, foi identificada como a responsável por estes atentados passados, assim como pelos ataques de 2001. Entretanto, o risco destes atores transnacionais era visto como um problema menor na agenda de Bush. Havendo, como indicou o antigo assessor de Clinton, Richard Clarke, uma certa displicência no trato desta questão por Bush.

Tais afirmações de Clarke foram apresentadas nas investigações da Comissão Bipartidária de 11/09 que também contou com membros do governo Bush e Clinton. Suas conclusões, a despeito destas denúncias e da divulgação de documentos controversos como o Presidential Daily Briefing de Agosto de $2001,{ }^{7}$ indicaram que teria sido impossível prever ou se antecipar a 11/09, devendo-se, entretanto, investir mais recursos no campo da segurança doméstica. Mesmo com estas conclusões, é fato, como se procurou indicar com a avaliação da plataforma externa de Bush, que o terrorismo não era inicialmente uma prioridade desta agenda, cujo foco eram os Estados e os temas tradicionais de poder.

Ainda que 11/09 tenha acontecido e que hoje a guerra contra o terrorismo esteja na lista de "primeira prioridade" do governo norte-americano, não houve, na prática, uma transformação significativa na postura de engajamento externo neoconservador. A despeito de uma breve volta ao multilateralismo para construir a coalizão inicial contra o Afeganistão, que culminou com a Operação Liberdade Duradoura em 2001 e que foi conduzida por Powell à luz da empatia inicial gerada pelos ataques, o curso da política externa de Bush permaneceu relativamente o mesmo desde o seu Internacionalismo Diferenciado de campanha.

A premissa da luta contra o terror como uma disputa militar foi consolidada, a despeito do caráter transnacional e multidimensional desta ameaça que

7 O briefing era intitulado "Bin Laden determinado a atacar os EUA" e dizia que "Membros da Al-Qaeda - incluindo alguns que são cidadãos norte-americanos - têm morado e viajado por anos dentro dos EUA. Este grupo, aparentemente, possui uma estrutura que poderia ajudar a dar apoio a ataques [...] Informações do FBI indicam padrões de atividade suspeita neste país, consistente com a preparação de seqüestros e outros tipos de ataque, incluindo a vigilância de prédios federais em Nova Iorque". Igualmente, a presidência foi acusada de ignorar as simulações do comando de defesa (Norad) que indicavam cenários de ataque muito parecidos a $11 / 09$. 
exigiria, para seu combate, instrumentos variados similares e não somente a força bélica. Os mecanismos pelos quais os norte-americanos optaram foram o ataque a Estados que são acusados de incentivar o terror, deixando de lado operações como espionagem, propaganda política, combate à lavagem de dinheiro, transformação das condições que geram as raízes destes movimentos fundamentalistas e antiamericanos como a pobreza e a miséria. Em linhas gerais, não houve avanço na compreensão da natureza assimétrica da guerra, na qual os EUA enfrentam grupos (e não só Estados-nação tradicionais) de origem privada e oponentes com recursos de poder extremamente inferiores. A inflexão esperada de retorno ao internacionalismo multilateral e de uma nova postura teve, portanto, breve duração.

Embora o objetivo declarado da presidência seja o combate ao terror e a sua associação com a tecnologia que leva à destruição massiva, os propósitos secundários, ou "não declarados" que se realizam por meio da guerra global aos novos inimigos, são ainda a supremacia militar convencional e no TMD, o relacionamento de comando com as demais potências, a opção unilateral em detrimento ao multilateralismo, a mudança de regime em nações hostis e o reposicionamento na Eurásia.

Tanto a nova Estratégia de Segurança Nacional, a Doutrina Bush de Setembro de 2002 (NSS/2002), como a prévia declaração do Eixo do Mal comprovam esta realidade. No caso do Eixo, cuja retórica lembra mais uma vez Reagan, temos a colocação dos inimigos da América, Irã, Iraque e Coréia do Norte, seguidos de Líbia, Síria e Cuba, indicando uma posição de ativismo para prevenir a expansão de suas ameaças. A força militar e pressões para a mudança de regime nestes Estados para sua transformação em nações livres são enfatizados, uma vez que suas presença e postura disseminam ameaças ao modo de vida norte-americano.

$\mathrm{Na}$ Doutrina, o tema é retomado, avançando ainda mais esta possibilidade de interferência e intervenção em nome da segurança em nações e regiões que lhes apresentem risco. Com isso, são desenvolvidos os conceitos de ação preventiva e preemptiva, que significam uma revolução tática na história da política externa norte-americana, abandonando a sua postura de contenção e dissuasão. No mundo do século XXI, os EUA reservam-se o direito e o dever de agir diante de ameaças iminentes a sua sobrevivência. No cenário de hoje, a combinação terror e proliferação de ADMs é definida como a maior ameaça à liberdade, cabendo aos EUA preservá-la e protegê-la. 
A ação preemptiva refere-se ao combate a riscos já existentes e de fácil percepção, enquanto a preventiva tem como objetivo impedir que situações percebidas como potencialmente ameaçadoras convertam-se em perigos reais. Ou seja, a ação preventiva antecipa-se à emergência destes perigos, buscando eliminá-los em seu estágio embrionário. Tal tarefa é extremamente complexa, dependendo de informações confiáveis de inteligência e avaliações equilibradas, que nem sempre garantem a eliminação do erro. Para o desenvolvimento de ambas, é preciso garantir a supremacia militar incondicional, havendo uma revisão da postura nuclear, considerando a sua possibilidade de uso, mesmo que o país não seja atacado por armamento similar ou que utilize este elemento decisivo contra nações não-nuclearizadas.

Estes movimentos podem ser realizados, caso necessário, independentemente de regras, organismos internacionais ou aliados e muitas vezes os norte-americanos se verão sozinhos em suas ações: um fardo da liderança considerado pela administração necessário e normal. Apesar de reconhecer a importância destas instâncias e a união entre as potências democráticas no mundo, a NSS afirma que o país não pode esperar pelos outros para agir, colocando-se em risco desnecessário. Mesmo com relação às demais potências, os EUA devem manter uma postura equilibrada, examinando a existência de seus potenciais de instabilidade e alinhamento, tendo como base o fato de que certas nações como Rússia, Índia e China passam por transições que merecem ser observadas de perto.

Em suas linhas gerais, a Doutrina Bush é a versão mais acabada das estratégias aqui abordadas, que puderam ganhar o mainstream da ação estratégica por meio da eleição de Bush em 2000, mas, principalmente, a partir de 11/09. Ao transformar a realidade de proteção incondicional do território em uma ilusão, os atentados terroristas trouxeram para a sociedade norteamericana a percepção do medo, favorecendo a consolidação desta agenda mais agressiva e unilateral. Dinâmica similar de endurecimento e validação de controles sociais, restrição às liberdades aplica-se à dimensão doméstica dos projetos neoconservadores.

Símbolo deste momento, o Ato Patriota colocado em prática já em 2001 impõe inúmeros constrangimentos sobre a liberdade de expressão, monitoramento da vida dos cidadãos, como permite às autoridades federais a prisão de suspeitos de terrorismo sem aviso prévio, seu isolamento, deportação e mesmo 
instauração de tribunais secretos. A revisão do conceito de tortura e a ampliação dos procedimentos de interrogatórios considerados "aceitáveis" também se incluem neste campo, com efeitos no tratamento dos prisioneiros em Guantanamo e, depois, no Iraque ocupado ${ }^{8}$ (o responsável por este Memorando polêmico será o hoje Ministro da Justiça do segundo gabinete Bush, Alberto Gonzáles).

A aplicação destes novos conceitos e visões culminou, em 2003, na Guerra do Iraque, e na consideração de novas operações militares em outros países como Irã, Coréia do Norte e Síria, demonstrando tanto os riscos quanto a lógica da doutrina. Para o Executivo norte-americano, o DOD e o NSC, esta guerra era apenas um encaminhamento natural da campanha contra o terror iniciado em 2001 com a operação no Afeganistão. Tradicional inimigo dos EUA, Saddam Hussein representava no Oriente Médio um ponto focal de instabilidade e risco, que, segundo estas avaliações, era capaz de promover ameaças reais a seus vizinhos dada a posse de ADMs e a seu comportamento conhecido de agressividade. Hussein teria sido, ao lado de Bin Laden, responsável por 11/09. Ambas as informações, apesar de não confirmadas, serviam como base de conquista de apoio doméstico, explorando o sentimento de insegurança vigente no país, sinalizando que era necessário, para a proteção dos EUA, uma ação preventiva.

A maioria da comunidade internacional não apoiava esta intervenção, não percebendo a existência deste risco iminente. Durante quase todo o ano de 2002, os EUA tentaram "provar seu caso" às Nações Unidas, conseguindo, finalmente a aprovação de uma dúbia resolução sobre a situação daquele país. Na resolução 1441 estabelecia-se que o Iraque sofreria "graves conseqüências" caso não aceitasse as demandas da $\mathrm{ONU}$, o que, para a presidência Bush, mesmo frente à oposição de importantes aliados como França e Alemanha, e de seu antigo inimigo russo e a não anuência da China, significou o mandato para a guerra. Apoiados por uma Coalizão da Vontade, na qual o único membro de destaque era a Grã-Bretanha (e o Japão, mas com muito menor participação), os EUA efetivamente fizeram a guerra, iniciando os ataques a Bagdá, em março de 2003.

8 A categoria "combatente inimigo" foi também apresentada neste momento, quando o governo foi criticado pelo tratamento dado aos prisioneiros da base militar, em discordância com os princípios da Convenção de Genebra. Porém, de acordo com esta visão, os prisioneiros não poderiam ser tratados nestes parâmetros, uma vez que eram membros de grupos terroristas e não de um Estado, como prevê a Convenção. 
Rapidamente, os ataques militares levaram à deposição de Saddam Hussein e seus aliados, ainda que este ditador só tenha sido capturado no final daquele ano, estando ainda seu julgamento pendente. De imediato, os norteamericanos anunciaram o sucesso da operação, instaurando um governo de transição que, dada a violência e instabilidade locais, foi trocado logo em seguida, permanecendo até hoje uma situação precária. ${ }^{9}$ Todavia, o "novo Iraque" foi sendo construído ao longo deste período, assim como o Afeganistão. Ambos possuem suas constituições e passaram por eleições, justamente demonstrando o processo de consolidação da liberdade e democracia no Oriente Médio, segundo as visões da presidência. Da mesma forma, o governo norte-americano indica a existência de avanço no processo de paz Israel/Palestina para a construção dos dois Estados (o Mapa da Estrada), beneficiando-se da morte de Arafat e da ascensão de um governo palestino moderado com Mazen, e da aliança prévia com Sharon.

Porém, as dificuldades relacionadas a estas duas operações militares conjuntas, que também levaram a presidência a moderar na ONU algumas posições anteriores, voltando a defender o multilateralismo, passaram a pesar nas pesquisas de popularidade e eleitorais em 2004, fazendo renascer a disputa que parecia decidida desde os atentados em 2001. Dentre estas, deve-se destacar o aumento crescente de baixas, as revelações de que as informações que levaram ao confronto no Iraque eram equivocadas, os escândalos de tortura, as denúncias de superfaturamento de empresas envolvidas na reconstrução como a Halliburton ligada ao Vice-Presidente e o início da "fuga" de aliados da Coalizão da Vontade, pressionados por suas populações que passaram a ver civis e soldados de suas nacionalidades seqüestrados e mortos, sofrendo ameaças (e ataques) terroristas em seu próprio território (o caso da Espanha é o mais conhecido, quando José Maria Aznar perdeu as eleições para Zapatero, depois dos atentados de Madrid em 11 de Março de 2004).

9 Pouco depois da instauração do governo de ocupação sob o comando de Jay Garner, os EUA o trocaram por Paul Bremer, um administrador civil. No aprofundamento da crise também aceitaram a presença da ONU que acabou resultando na morte em um atentado de Sérgio Vieira de Mello em agosto de 2003, enviado especial da instituição. Na seqüência, os EUA aumentaram o número de tropas, constituíram um governo interino local o CGI (Conselho de Governo Iraquiano), anteciparam a transferência de soberania para junho de 2004 e mantiveram as eleições de janeiro de 2005, na qual os xiitas alcançaram a maioria na Assembléia que definirá o novo governo e constituição até o final de 2005. Para uma leitura mais aprofundada destes temas ver artigos de Pecequilo (2002-2004). 
Estes fatos, somados aos problemas econômicos da presidência Bush e a permanência da sensação de insegurança interna trouxeram temores aos republicanos de que a reeleição poderia estar ameaçada. Contudo, a demora democrata em definir uma agenda propositiva (mesmo com antecipação da chapa contra Bush, John Kerry e John Edwards), a ausência de líderes, de uma aproximação com a plataforma de centro-moderada aqui descrita e o peso do terror acabaram não permitindo a este partido a reconquista da Casa Branca.

Ao longo de toda a campanha, os neoconservadores demonstraram-se hábeis em explorar o medo da população, instrumentalizando o sistema de alerta de novos atentados terroristas, vídeos de Bin Laden, desconstruindo a figura de Kerry como um homem indeciso e fraco. Mais ainda preservaram sua coesão e união em torno do programa de governo que já vinha sendo defendido e implantado desde 2000, afirmando sua coerência e visão. Ao serem pressionados pelas deficiências e contradições da política externa, o aumento dos custos da guerra, a violência, o déficit, os republicanos investiam na discussão de temas paralelos, mas polêmicos, como casamento de homossexuais e a emenda constitucional para sua proibição e invertiam o argumento em seu favor.

O exemplo mais conhecido desta tática foi observada no caso da ausência de ADMs no Iraque, justificativa utilizada para encaminhar a guerra: ao ser confrontado com os fatos Bush até mesmo chegou a admitir um certo exagero nas informações. Entretanto, com ou sem ADMs, Saddam Hussein era um risco real para a segurança regional e mundial e sua deposição foi correta, servindo, adicionalmente, como exemplo demonstrativo, para outros ditadores. Focada no terror, no medo, na fé e no moralismo, a campanha beneficiou Bush, minimizando seus problemas com a perda de empregos, desaceleração econômica e, como analisado, o levou à reeleição pela promessa da continuidade e aprofundamento de suas agendas.

\section{O segundo mandato (2005)}

Como destacado no início do texto, ainda que Bush tenha sido reeleito com números significativos e seu partido tenha consolidado sua posição no sistema político norte-americano, quase metade do país não compartilha de 
seu programa de governo interno e externo. Entretanto, a continuidade de iniciativas vem caracterizando este período inicial da presidência Bush, indicando a busca da solidificação de suas posições políticas e prioridades.

No gabinete, o perfil neoconservador foi reforçado com a saída, já anunciada desde a campanha, de Collin Powell do Departamento de Estado e a sua substituição por Condoleezza Rice, antes Assessora de Segurança Nacional. Para o cargo de Rice foi indicado seu antigo vice no NSC, Stephen Hadley, garantindo a unidade na condução de políticas entre estas duas instituições. Tal unidade foi ainda reforçada pela permanência de Dick Cheney na VicePresidência e de Donald Rumsfeld em seu cargo no DOD, mesmo com todas as críticas a sua estratégia militar no Iraque ${ }^{10}$ e sua posição frente à questão da tortura em instalações militares norte-americanas. No que se refere à tortura, mais protestos foram realizados quando da indicação, e confirmação, de Alberto Gonzales à frente do Ministério da Justiça. Assim, reforçou-se a coesão, homogeneidade e estabilidade da equipe de governo.

Os discursos de posse de Bush em janeiro, e seu State of Union Address, logo na seqüência, somente confirmaram esta tendência, indicando a permanência da Doutrina Bush e das linhas do conservadorismo com compaixão. Em ambos, Bush reafirmou a prioridade de, por meio de ações preventivas e preemptivas, dar continuidade a sua guerra global contra o terror, ajudando as demais nações a lutar contra os inimigos da liberdade, seja por meio de novas intervenções militares, ou por meio de interferências políticas. Mais uma vez, foi destacado o perigo representado pelos membros do Eixo do Mal, Coréia do Norte e, principalmente, Irã e Síria, e alertanda da permanente disposição norte-americana em defender-se e disseminar a liberdade. ${ }^{11}$

Ainda que novas intervenções preventivas não tenham sido anunciadas e que sua hipótese tenha sido afastada pelo próprio Bush e Rice, não é possível descartá-las por completo, dada a visão tática da presidência. Porém, no curto prazo a sua probabilidade é baixa devido a impedimentos logísticos, uma vez

10 O conceito de Rumsfeld de "choque e terror", para os críticos, é o responsável pela precariedade das condições iraquianas, uma vez que a presença de tropas é vista como insuficiente para a estabilização local desde o início da operação.

11 De acordo com Charles Krauthammer (2004), esta postura denominada de "Realismo Democrático" fortalece as posições norte-americanas em áreas estratégicas de forma pragmática, sem abandonar seus mais altos ideais de democracia e progresso. 
que tropas norte-americanas já estão engajadas em duas frentes, o que dificulta uma nova ação no Oriente Médio, e os custos humanos e financeiros de novas operações. Para isso, primeiro, seria preciso uma maior estabilização no Iraque ou uma transferência de tropas para um corpo multilateral o que não parece provável. Além disso, no caso da Coréia, há uma objeção adicional: a sua localização na Ásia e o envolvimento de outras potências na região, China, Rússia, Japão e Coréia do Sul, que dificultam ações mais livres dos EUA.

É importante retomar a questão do multilateralismo, pois, como mencionado, é ainda pequena a chance de que outras nações, além daquelas já envolvidas originalmente na guerra do Iraque, passem a atuar neste país. A despeito de discursos conciliatórios com os antigos aliados europeus dos quais se distanciou naquele momento, como França e Alemanha, e Rússia, os EUA não dão sinais definitivos de que sua política mudará. As indicações, como em oportunidades prévias, são ambíguas: ao mesmo tempo em que reafirma a Doutrina preventiva, Bush fala em reconciliação multilateral, mas sem construções práticas que sustentem e dêem confiabilidade a esta afirmação.

Tal cenário foi revelado com clareza no recente tour de Rice, Rumsfeld e Bush à Europa, no qual comunicados conjuntos com estes parceiros foram anunciados, mas sem eliminar fissuras ou posturas independentes. Destacase, particularmente, a situação da Rússia: Bush e Putin fizeram uma declaração contra a proliferação das ADMs na Coréia do Norte e Irã e, poucos dias depois, Putin assinou, mesmo frente às objeções dos EUA, um acordo tecnológico com o Irã para a construção de uma central nuclear neste país, também mantendo sua parceria com a China na área. Na Europa, à exceção da Inglaterra, França e Alemanha aparam arestas, mas as divergências na Otan e com relação a Pesc (Política Externa e de Segurança Comum) permanecem. Novas crises como as do Iraque as revelarão novamente, podendo ampliar a distância entre os aliados transatlânticos.

No resto do mundo, a postura é semelhante, aproximação com desconfiança, não se percebendo uma alteração acentuada nas posturas republicanas, ainda que alguns antigos críticos hoje pareçam apoiar fenômenos como a emergência da democracia no Oriente Médio, aparentemente desconsiderando as origens deste movimento. No que se refere ao Brasil, os temas centrais 
do relacionamento bilateral não parecem sofrer mudança: Alca, programa nuclear e relações políticas de alto nível. Igualmente, as preferências republicanas por temas tradicionais ligados ao poder militar não indicam grandes avanços nas negociações comerciais da OMC. ${ }^{12}$

Em termos domésticos, a perspectiva de continuidade e avanço é até maior do que no plano externo apesar dos resultados de novembro passado. A recuperação moderada ainda não ocorreu para "quebrar" o controle neoconservador que, na prática, como indicado, apenas se expandiu. Com isso, Bush poderá, por meio do comando do Executivo, Legislativo e governos estaduais relevantes como Flórida, Texas e Califórnia, dar seqüência ao processo de solidificação nas estruturas internas do poder. A possibilidade de nomeação de juízes conservadores à Suprema Corte, poderá alterar o equilíbrio com os moderados, uma tradição no judiciário. Frente a isso, preocupam a reversão de direitos civis específicos, como o aborto preocupa (uma agenda de direito à vida foi destacada por Bush), e de proteção ao cidadão em geral.

No campo da política econômica, novamente Bush reafirmou sua agenda e a "fórmula" republicana de cortar impostos para fazer a economia crescer, a despeito do crescente aumento dos déficits pelo incremento destes cortes e dos gastos militares. Neste cenário, a promessa de redução do déficit pela metade até o final deste segundo mandato é duvidosa. Outro conceito lançado que engloba esta política econômica, assim como a social acima é o de Ownership Society, visando à expansão dos direitos individuais e sua capacidade econômica, prometendo uma reforma "revolucionária" em setores como previdência e saúde. Liberar as ações individuais, os verdadeiros valores e direitos nacionais estão nesta definição de progresso pessoal sem interferência governamental. A margem de manobra e influência na cultura, saúde, previdência e educação são amplas, podendo redesenhar a sociedade norteamericana de forma paradoxal: uma relativização de conquistas no campo social e civil, aliado à expansão da ação econômica sem constrangimentos.

Contudo, realizar previsões em estágios tão iniciais de governo e traçar suas linhas até o seu encerramento é arriscado, devendo-se destacar que estas

12 A eleição de Kerry poderia ter trazido esta alteração de postura, pelo menos em termos táticos, recuperando o internacionalismo multilateral. Contudo, a prioridade no terrorismo seria mantida e, talvez, também certo protecionismo econômico. 
avaliações referem-se, basicamente, a tendências de curtos e médios prazos. Se em termos externos não se deve esquecer da possibilidade real de ajustes para um perfil mais moderado, relembrando a administração Reagan, no campo doméstico, as pressões do emprego e do déficit também poderão trazer mudanças. Afinal, em 2006, os eleitores norte-americanos irão novamente às urnas nas eleições de meio de mandato, justamente avaliando a performance inicial desta nova presidência Bush. Porém, já com um certo recuo, é possível indicar algumas conseqüências mundiais e nacionais do primeiro mandato que, caso os rumos atuais permaneçam, somente se acentuarão.

O sistema internacional pós-Doutrina G. W. Bush revela traços de insegurança e instabilidade mais elevados do que os anos Bush pai e Clinton, tendo esta transição se iniciado antes de 11/09, derivada da postura unilateral republicana. Frente a uma superpotência hegemônica agressiva que transformou seu estilo de dominação, a maioria das nações passou a buscar seu fortalecimento e autonomia, ensaiando parcerias em nível global. A Guerra do Iraque, o eixo Paris-Berlim-Moscou, as parcerias China-Rússia, China-EU, China-América Latina e UE-América Latina, são alguns movimentos destes ensaios de coalizão anti-hegemônica que poderão levar a alterações de equilíbrio. Ao mesmo tempo, a doutrina preventiva norte-americana incentivou, e facilitou, ações preventivas semelhantes de outros Estados. Por fim, a relativização do multilateralismo enfraquece canais alternativos de domínio norteamericano e negociações entre as nações, podendo reverter a política mundial aos seus estágios interestatais pré-1945.

Paralelamente, a ampliação da agenda interna em meio à transição e divisão populacional abordada também poderá levar a fissuras e fragmentações, fragilizando aquela que é a mais importante base de poder da hegemonia: a sua força nacional. Outra raiz corrói-se, a do poder econômico, comercial e financeiro, por meio da perda de mercados e da ampliação dos déficits gêmeos. Com isso, não causa estranheza que, neste início de segundo século americano, assista-se à retomada de um debate que marcou, como indicado, $\mathrm{o}$ final da década de 1980 e o começo da seguinte, a do declínio e renovação da América.

Os termos do debate são similares: para os declinistas, o país desmonta sua projeção externa e interna pelo acúmulo de dívidas e um aumento de compromissos externos, culminando na superextensão imperial, observando 
uma quebra do consenso interno e crise econômica; para os atuais renovacionistas, os déficits internos e a dívida externa não representam problemas, mas sim formas modernas de inserção, que ressaltam a existência de um cenário interdependente entre as principais economias, lideradas pelos EUA, ajustando-se o campo doméstico. ${ }^{13}$

Deve-se mencionar, que estes renovacionistas diferenciam-se da corrente original da qual faziam parte Nye Jr. e mesmo Brzezinski, que viam estes problemas como preocupantes e pediam sua correção e o fim da complacência. No diálogo atual, inclusive, Nye e Brzezinski estão mais próximos dos novos declinistas, como Emmanuel Todd, ao indicar o processo de desconstrução hegemônica da presidência Bush, realizado por meio da quebra de consenso e da democracia interna e externa, da visão limitada que enfatiza só o hard power e do incentivo ao antiamericanismo. Por meio desta combinação de tensões, a fragilidade da liderança será produzida, havendo um crescente distanciamento entre as realidades e possibilidades do exercício do poder norte-americano e de sua reformulação.

Ao longo de sua história, os EUA acostumaram-se a enfrentar inimigos externos, administrando enquanto isso suas contradições internas, como já nos revelaram os momentos de crise da Guerra da Secessão, e os movimentos dos direitos civis, alcançando, apesar das dificuldades, novos diálogos e pontos de equilíbrio. Em tal contexto, a partir das disputas hegemônicas domésticas e externas, a inovação e o consenso tendiam a prevalecer, fortalecendo o país e sua posição internacional por meio destes antagonismos Nas últimas décadas, esta dinâmica demonstra sinais de enfraquecimento, prevalecendo, em certos momentos, a sua própria negação, contrariando a natureza original da democracia norte-americana: a da inovação e da ousadia, de seus erros reconhecidos, e de seus acertos expandidos.

13 No texto de Levey e Brown (2005) em Foreign Affairs este argumento é percebido. De acordo com estes autores, questionando o que definem como os "céticos da hegemonia", a economia norte-americana permanece altamente competitiva e o dólar central uma vez que os EUA continuam exercendo um papel de liderança política avançada no mundo, agregando credibilidade a estas ações e a sua economia. 


\section{Referências}

BERGER, Samuel R. Foreign policy for a democratic president. Foreign Affairs, mai.-jun. 2004. Disponível em www.foreignaffairs.org.

BOOT, Max. Think again: neocons. Foreign Policy, jan.-fev. 2004. Disponível em www.foreignpolicy.com.

BRZEZINSKI, Zbigniew. The choice. New York: Basic Books, 2004.

CASSE, Daniel. Is Bush a conservative? Commentary, february 2004. Disponível em www.commentarymagazine.com.

DAALDER, Ivo H.; LINDSAY, James M. America unbound. Washington: Brookings Institution, 2003.

GADDIS, John Lewis. Grand strategy in the second term. Foreign Affairs, v. 84, n. 1. jan.-fev. 2005.

HAGEL, Chuck. A republican foreign policy. Foreign Affairs, v. 83, n. 4, p. 64-76, jul.-ago. 2004.

HIRSH, Michael. Bush and the world. Foreign Affairs, v. 81, n. 5, p. 18-43, set.-out. 2002.

HUNTINGTON, Samuel P. Who are we? New York: Simon and Schuster, 2004.

IKENBERRY, G. John. America's imperial ambition. Foreign Affairs, v. 81, n. 5, p. 44-60, set.-out. 2002.

JOHNSON, Chalmers. The sorrows of empire. New York: Metropolitan Books, 2004.

KAGAN, Robert; KRISTOL, William (org.). While America sleeps. San Francisco: Encounter Books, 2000.

- Present dangers: crisis and opportunity in America foreign and defense policy. San Francisco: Encounter Books, 2000.

KRAUTHAMMER, Charles. The unipolar moment. Foreign Affairs, v. 1, n. 70, inverno 1990/1991. p. 23-33.

. In defense of democratic realism. The national interest, p. 15-25, primavera 2004.

KRISTOL, Irving. Neo conservantism. Chicago: Elephant Books, 1995.

LEVEY, David H; BROWN, Stuart S. The overstretch myth. Foreign Affairs, mar.abr. 2005. Disponível em www.foreignaffairs.org.

NORAD. 20 de abril de 2004. Disponível em www.usatoday.com.

NYE JR., Joseph S. O paradoxo do poder americano. São Paulo: Unesp, 2002.

PECEQUILO, Cristina S. A politica externa dos Estados Unidos: continuidade ou mudança? Porto Alegre: Ed. Ufrgs, 2003.

. Artigos disponíveis em www.relnet.com.br e www.ilea.ufrgs.br/nerint. 
PRESTOWITZ, Clyde. Rogue nation. New York: Basic Books, 2003.

Revista Idéias. Terrorismo e guerra. Campinas: Ifch/Unicamp v. 10, n. 2, 2003.

TODD, Emmanuel. Após o império. Lisboa: Edições 70, 2002.

\section{Imprensa}

Election Data 200-2004. Disponível em www.fec.gov.

Election Results Special, America Votes 2004. Disponível em www.cnn.com.

CLEMONS, Steven. US: all powerful but powerless. Le Monde Diplomatique, edição inglesa, out. 2001.

GORCE, Paul-Marie. The hawk doctrine. Le Monde Diplomatique, edição inglesa, set. 2002.

GOLUB, Philip. America's imperial longings. Le Monde Diplomatique, edição inglesa, jul. 2001. mar. 2003.

. United States: inventing demons. Le Monde Diplomatique, edição inglesa,

HALIMI, SERGE. Election 2004 special: The United States Bush Record. Le monde Diplomatique, edição inglesa na internet.

- What's the matter with West Virginia. Le Monde Diplomatique, edição inglesa na internet.

KLARE, Michael. United States: energy and strategy. Le Monde diplomatique, nov. 2002.

LAZARE, Daniel. The backward state of Texas. Le Monde Diplomatique, edição inglesa, set. 2000.

America's patriot games. Le Monde Diplomatique, edição inglesa, jan. 2002.

American caesar. Le Monde Diplomatique, edição inglesa, ago. 2002.

LE CARRÉ, John. Loucura histórica toma conta dos EUA. FSP, 26/01/2003.

\section{Documentos}

BUSH, George W. State of the Union address 2002.

—. Innaguration Speech. January 2005.

- State of the Union Address. 2005.

National security strategy for a New Century, White House, NSC, 1993 e 2002

President's Daily Brief for August 6, 2001. April 11, 2004, Disponível em www.nytimes.com.

RICE, Condoleezza. Innaugural speech as Secretary of State. Jan. 2005. Disponível em www.state.gov.

Recebido em 10 de março de 2005 e aprovado em 20 de julho de 2005 